\title{
Diffuse interstitial fibrosis in well-controlled hypertension
}

\author{
Thomas A Treibel ${ }^{1 *+}$, Filip Zemrak ${ }^{3+}$, Steven K White ${ }^{1,2}$, Daniel Sado ${ }^{1}$, Sanjay M Banypersad ${ }^{1}$, Viviana Maestrini ${ }^{1}$, \\ Mark Caulfield ${ }^{3}$, Steffen E Petersen ${ }^{3}$, James Moon ${ }^{1}$ \\ From 16th Annual SCMR Scientific Sessions \\ San Francisco, CA, USA. 31 January - 3 February 2013
}

\section{Background}

Diffuse myocardial fibrosis (DMF) is an important factor in cardiac disease but until recently could only be accurately assessed with biopsy. We hypothesised that DMF measured by EQ-CMR is elevated in isolated systemic hypertension. As such DMF may be a key biomarker in assessing the cardiac effects of systemic hypertension.

\section{Methods}

ECV measurement was by EQ-CMR. The T1 mapping sequence was ShMOLLI. The contrast agent was Gadoterate meglumine (Dotarem) at $0.1 \mathrm{mmol} / \mathrm{Kg}$ (bolus) plus infusion at 15 minutes at $0.0011 \mathrm{mmol} / \mathrm{kg} / \mathrm{min}$. CMR was at $1.5 \mathrm{~T}$ (Siemens Avanto).

ECV was measured in 43 well-controlled hypertensive patients from a specialist tertiary centre (median age 56, range 21 to $78,55 \%$ male) and 50 healthy volunteers (median age 47, range 28 to $69,58 \%$ male).

ECV was calculated by ECV $=(1$-hematocrit $) \times(1 / \mathrm{T} 1)$ myo $\div(1 /$ T1 1$)$ blood.

\section{Results}

The 43 hypertensive subjects had a significantly higher ECV than the 50 gender-matched normotensive controls (0.274 versus $0.261, p=0.018$; Figure 1$)$. Although the mean mass index $\left(85.0 \mathrm{~g} / \mathrm{m}^{2}\right.$ versus $\left.62.7 \mathrm{~g} / \mathrm{m}^{2}\right)$ was significantly higher in hypertensive subjects, there was no correlation between ECV and mass index.

Only 16 hypertensive subjects (37\%) had a mass index outside the normal range (male $>90 \mathrm{~g} / \mathrm{m}^{2}$; female $>78 \mathrm{gm}^{2}$ [JCMR 2006, 8, 417-426]), and their ECV was significantly higher than those without elevated mass index ( 0.285 versus $0.262, p=0.005$; Figure 2$)$. As expected, this

† Contributed equally

${ }^{1}$ The Heart Hospital Imaging Centre, University College London, London, UK Full list of author information is available at the end of the article sub-group had higher systolic and diastolic blood pressures on ambulatory monitoring (168/96 versus 134/78, $p<0.05)$, larger end-systolic and diastolic volumes and left atrial areas.

\section{Conclusions}

ECV is significantly higher in subjects with well-controlled isolated, systemic hypertension than in normotensive, healthy volunteers. Elevated ECV was predominantly measured in patients with higher mean blood pressures and hence increased mass index. The overlap between the two cohorts can therefore reflect the success of effective blood pressure control, affecting not only LVH, but also diffuse fibrosis. There was no overall correlation between mass index and ECV, which

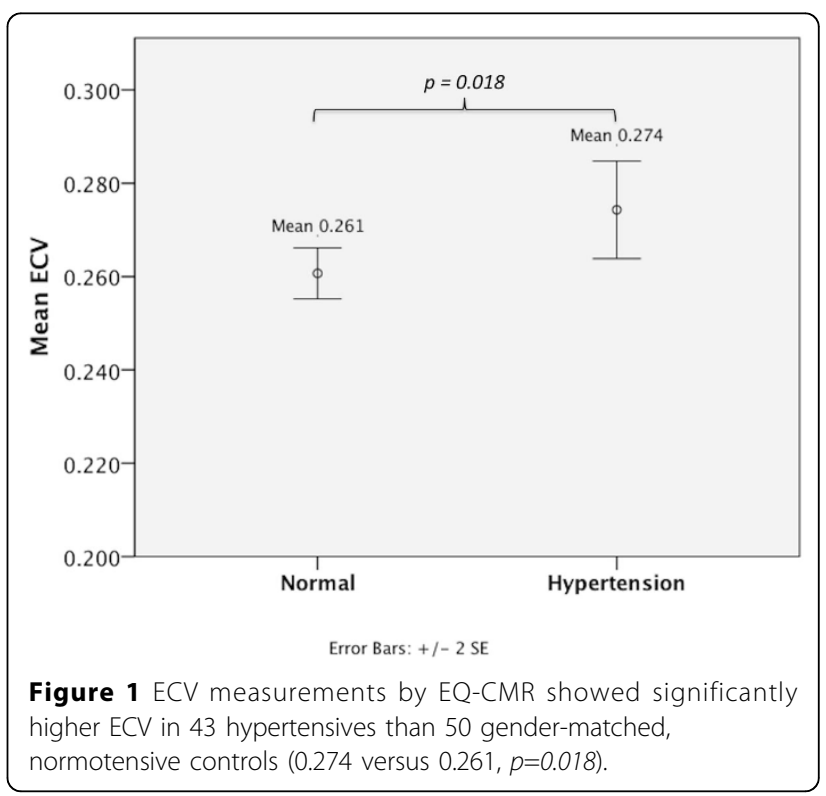




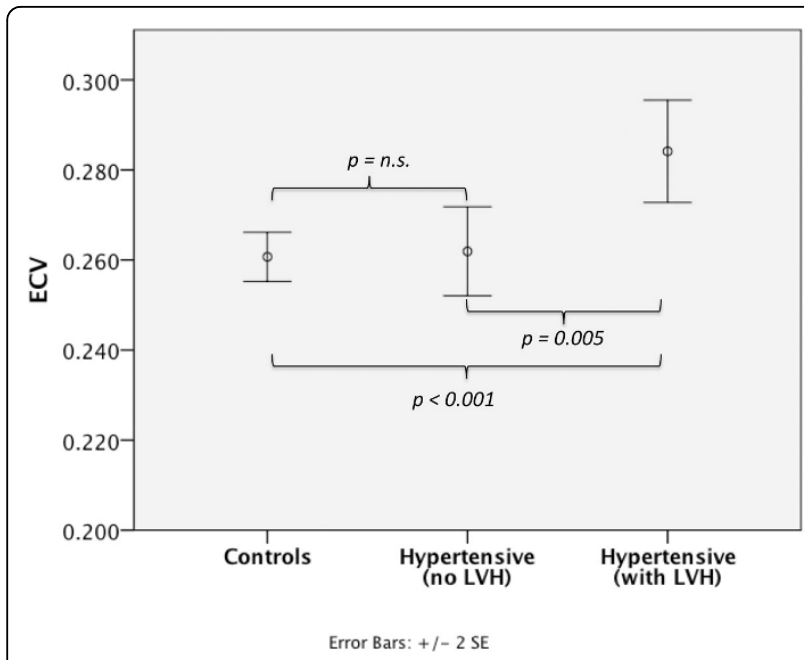

Figure 2 ECV measurements in hypertensives with elevated left ventricular mass index (37\%) were significantly higher than those without elevated mass index (0.285 versus $0.262, p=0.005$ ).

may suggest that ECV and by inference DMF is an independent factor in systemic hypertension.

\section{Funding}

British Heart Foundation; National Institute for Health Research.

\section{Author details}

${ }^{1}$ The Heart Hospital Imaging Centre, University College London, London, UK. ${ }^{2}$ The Hatter Cardiovascular Institute, University College London Hospitals NHS Trust, London, UK. ${ }^{3}$ Cardiovascular Biomedical Research Unit, Barts and the London School of Medicine and Dentistry, Queen Mary University of London, London, UK.

Published: 30 January 2013

doi:10.1186/1532-429X-15-S1-P251

Cite this article as: Treibel et al: Diffuse interstitial fibrosis in wellcontrolled hypertension. Journal of Cardiovascular Magnetic Resonance 2013 15(Suppl 1):P251.

\section{Submit your next manuscript to BioMed Central} and take full advantage of:

- Convenient online submission

- Thorough peer review

- No space constraints or color figure charges

- Immediate publication on acceptance

- Inclusion in PubMed, CAS, Scopus and Google Scholar

- Research which is freely available for redistribution

Submit your manuscript at www.biomedcentral.com/submit 